\section{The role of Tranexamic Acid in bleeding control during Total Hip Arthroplasty: An analysis}

\author{
Adrienne de Lemos Basto ${ }^{1}$, Willian Colleti \\ Hagemann ${ }^{1}$, Max Rogério Freitas Ramos ${ }^{2 \star}$
}

'Orthopaedic Resident by Federal University of the State of Rio de Janeiro UNIRIO ${ }^{2}$ Associate Professor of Orthopedics and Traumatology, Federal University of the Rio de Janeiro State UNIRIO, Head of Orthopedic Clinics at Gaffrée Guinle University Hospital HUGG
Address for correspondence: Max Rogério Freitas Ramos, Associate Professor of Orthopedics and Traumatology, Federal University of the Rio de Janeiro State UNIRIO, Head of Orthopedic Clinics at Gaffrée Guinle University Hospital HUGG.

Email: drmaxramos@hotmail.com

How to cite this article: Basto ADL, Hagemann WC, Ramos MRF. The role of Tranexamic Acid in bleeding control during Total Hip Arthroplasty: An analysis. G Med Sci. 2020; 1(6): 013-021.

https://www.doi.org/10.46766/thegms.ortho.2011081

Copyright: (c) 2020 Max Rogério Freitas Ramos, Adrienne de Lemos Basto, Willian Colleti Hagemann. This is an Open Access article distributed under the Creative Commons Attribution License, which permits unrestricted use, distribution, and reproduction in any medium, provided the original work is properly cited.

Disclaimer: The views expressed in this article represent those of the authors and no other entity or organization.

\title{
Abstract
}

Objective: This prospective cohort study analyzed the role and use of tranexamic acid (ATX) in control of bleeding in patients undergoing primary total hip arthroplasty. The observation was based on administration of a single dose of venous tranexamic acid $20 \mathrm{mg}$ per $\mathrm{kg}$ of weight of patients after anesthetic induction.

Methods: A group of 40 patients admitted for the treatment of hip coxarthrosis during December 2017 to December 2019 were evaluated in this study. In this group, 20 patients used ATX and others were related in the control group.

Inclusion criteria included: Idiopathic coxarthrosis, age between 55-65 years.

Exclusion criteria included: Non-idiopathic coxarthrosis, age less than 55-years and above 65-years, lower limb deformity, body mass index greater than $35 \mathrm{~kg} / \mathrm{m}^{2}$ and joint instability.

We compared the mean pre-operative and post-operative bleeding of both groups and evaluated the effectiveness of ATX in reducing bleeding. Perioperative control was accounted for through the aspirator collectors during the surgery and the bleeding absorbed by the surgical compresses. Postoperative control was assessed by suction drainage debit in the first 48 postoperative hours. We also evaluated the need for blood transfusion between the groups.

Results: The variables investigated in the study were: Weight of Blood Compresses, Collector and Pre-Bleeding, Post Bleeding and Total Bleeding. These variables presented statistically significant values. At $5 \%$ significance level they rejected the hypothesis that the Control and Test groups had the same bleeding. According to this result, we reached to a conclusion that at a level of $5 \%$ of significance the drug Transamin has effect in reducing the variables that represent the bleeding of patients, excluding the variable Quantity of Blood Compresses.

Conclusion: The use of intravenous ATX was effective in reducing bleeding in patients undergoing primary total hip arthroplasty.

Keywords: tranexamic acid; primary total hip arthroplasty; bleeding. 


\section{Introduction}

In United States, Total Hip Arthroplasty (THA) is considered as one of the most common elective procedures. One of the prevailing factors is the increase in life expectancy measures. THA is considered to be a major surgery and blood loss is predicted therefore the need for blood transfusion becomes a necessity in some settings. Both allogeneic transfusion and blood loss can potentially result in substantial increases in costs and significant complications such as postoperative infection, delayed physical recovery, increased hospital stay and increased mortality [1].

Perioperative blood loss can vary from $300 \mathrm{ml}$ to $2000 \mathrm{ml}$ in primary THA procedures [2][3]. These complications may be more evident in patients with pre-existing medical comorbidities, including degree of deformity, heart, lung, kidney disease and surgical time [4][5].

Even though several rigorous tests are conducted before blood transfusion, it causes significant inherent risks including hemolytic reactions, inflammatory tissue damage, infection, among other blood-borne diseases, as well as the immune modulation caused by allogeneic transfusion, contamination and immunological reactions [6][7].

In view of the higher financial cost and these possible complications and adverse events associated with blood loss and blood transfusion, it is necessary to investigate and discover strategies to reduce bleeding in THA.

ATX is an antifibrinolytic, inhibits the dissolution of clots by blocking the formation of plasma by not activating the coagulation cascade, reducing the intensity and risks of bleeding [8-10].

The objective of this study was to analyze the effectiveness of ATX in reducing bleeding in Hip Total Arthroplasty surgeries and to ascertain reduction in the need for blood transfusion.

\section{Method}

This is a prospective cohort study conducted on group of 40 patients admitted for the treatment of hip coxarthrosis during December 2017 to December 2019. This work was approved by the Research Ethics Committee of the Center for Biological and Health Sciences at the Federal University of the State of Rio de Janeiro (UNIRIO). CAAE 80969517.0.0000.5258.

Inclusion criteria included: Idiopathic coxarthrosis, age between $55-65$ years.

Exclusion criteria included: Non-idiopathic coxarthrosis, age less than 55-years and above 65-years, lower limb deformity, body mass index greater than $35 \mathrm{~kg} / \mathrm{m}^{2}$ and joint instability.

The perioperative bleeding estimated in the study reflected the count in the surgical site aspirators during the surgery plus the bleeding absorbed by the surgical compresses. Postoperative bleeding was considered and estimated by the flow of vacuum drains installed during the first 48 hours after surgery.

The same team participated in the surgery of the selected patients. The surgical technique involved a cutaneous incision in the hip lateral midline, followed by soft tissue dissection and Hardinge Trans-gluteal approach, joint debridement, soft tissue balance, femoral neck osteotomy, acetabular and femoral prepare, and hip replacement with cementless prosthesis.

Hemostasis care was observed and Vacuum suction drains were positioned to allow adequate drainage of the surgical wound in the postoperative period for 48 hours. Tranexamic acid was used in each patient after anesthetic induction, intravenously, in a single dose (20 mg per $\mathrm{kg}$ of weight).

Patients who met the selection criteria were divided into two groups. In group A (test), with 20 patients, $20 \mathrm{mg}$ per $\mathrm{kg}$ of weight, intravenous, of ATX was administered after anesthetic induction. In group B (control), with 20 patients, ATX was not administered. The patients involved in the study remained hospitalized for 48 hours postoperatively, in order to identify possible complications related to the use of the drug, especially those resulting from thromboembolic events, such as venous thrombosis, pulmonary embolism, arterial occlusions, renal failure, etc. After this period, we started periodic outpatient monitoring.

The results were expressed as means. For comparisons, Student's t-test or Mann-Whitney test was used, when appropriate. The statistically significant results were accepted with $\mathrm{p}<0.05$. To verify homogeneity in the researched samples, the Shapiro-Wilk test was performed.

\section{Results}

The variables investigated in this study were: surgery side, age, number of blood compresses, weight of blood compresses (in grams), preoperative collector (in $\mathrm{ml}$ ), blood in the compress (in $\mathrm{ml}$ ), perioperative bleeding (in $\mathrm{ml}$ ), postoperative bleeding (in $\mathrm{ml}$ ) and total bleeding (in $\mathrm{ml})$. 


\section{Exploratory Analysis}

Table 1: A summary of control group variables and respective measures

\begin{tabular}{|l|l|l|l|l|l|l|}
\hline Variables & Mínimum & Q1 & Median & Average & Q3 & Maximum \\
\hline Age & 55,0 & 55,6 & 59,0 & 58,4 & 61,0 & 65,0 \\
\hline Quantity of soiled compresses & 10,0 & 20,5 & 23,0 & 22,1 & 24,0 & 30,0 \\
\hline Weight of blood compresses & 414,0 & 667,0 & 710,0 & 763,7 & 926,0 & 1028,0 \\
\hline Collector & 80,0 & 200,0 & 320,0 & 295,0 & 400,0 & 500,0 \\
\hline Blood in the compress & 84,0 & 129,0 & 173,0 & 206,1 & 264,0 & 428,0 \\
\hline Bleeding per & 164,0 & 399,0 & 503,0 & 502,0 & 631,0 & 726,0 \\
\hline Post bleeding & 640,0 & 735,0 & 840,0 & 904,7 & 1010,0 & 1350,0 \\
\hline Total bleeding & 1064,0 & 1191,0 & 1359,0 & 1407,0 & 1594,0 & 1898,0 \\
\hline
\end{tabular}

Table 2: A summary of the variables in the Test group and respective measures

\begin{tabular}{|l|l|l|l|l|l|l|}
\hline Variables & Mínimum & Q1 & Median & Average & Q3 & Maximum \\
\hline Age & 55,0 & 55,3 & 56,5 & 57,0 & 59,8 & 65,0 \\
\hline Quantity of soiled compresses & 9,0 & 14,0 & 19,0 & 19,1 & 24,0 & 35,0 \\
\hline Weight of blood compresses & 277,0 & 547,0 & 652,0 & 656,0 & 724,5 & 1092,0 \\
\hline Collector & 25,0 & 72,5 & 120,0 & 146,6 & 205,0 & 400,0 \\
\hline Blood in the compress & 79,0 & 160,5 & 205,0 & 235,7 & 306,0 & 465,0 \\
\hline Bleeding per & 174,0 & 265,5 & 358,0 & 381,7 & 461,0 & 865,0 \\
\hline Post bleeding & 320,0 & 571,5 & 670,0 & 708,8 & 900,0 & 1250,0 \\
\hline Total bleeding & 633,0 & 951,5 & 1023,0 & 1090,0 & 1194,5 & 1630,0 \\
\hline
\end{tabular}

The Table 3 below shows the summary measures of Total Bleeding per operated side.

Table 3: A summary of total bleeding per operated side and respective measures

\begin{tabular}{|l|l|l|l|l|l|l|}
\hline Groups & Minimum & Q1 & Median & Average & Q3 & Maximum \\
\hline RIGHT SIDE & 854,0 & 1084,0 & 1244,0 & 1272,0 & 1475,0 & 1694,0 \\
\hline LEFT SIDE & 633,0 & 997,5 & 1143,0 & 1233,5 & 808,0 & 1898,0 \\
\hline
\end{tabular}

The above-mentioned data shows that the distributions of the variables were similar. The same data was viewed in the form of boxplots (Figure 1). This showed that both sides had a similar distribution of bleeding, generating an indication that there is no difference in bleeding between the operated sides excluding the use of the medicine. 


\section{Figure 1: Total bleeding per operated side}

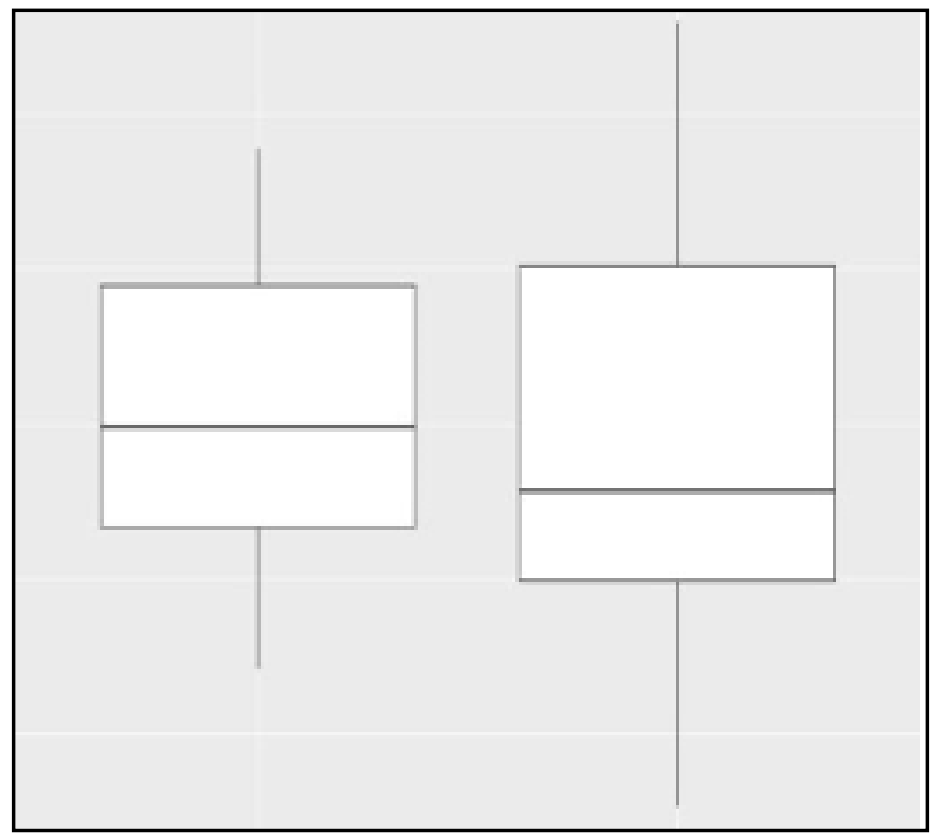

We observed that the test group on both sides operated on had less bleeding than the control group (Figure 2).

Figure 2: Total bleeding per side Operated according to treatment groups

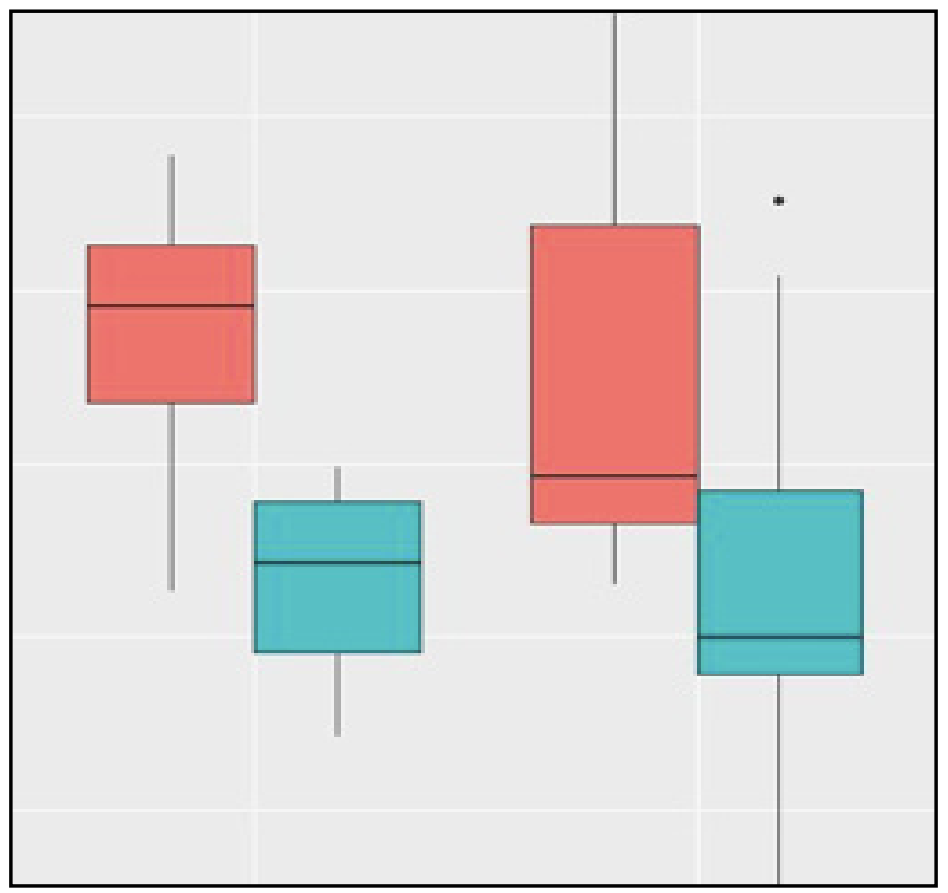

The age analysis was done from the median age and for this purpose we created the Age Range variable. We obtained a median of 59 and two new options for a new variable created: "Age group > 59 years old" and "Age group < 59 years". In comparison to the analysis of the operated sides, we observed that the Age Group variable has differences in distributions between the Age Group classes (Table 4 and Figure 3). The older group had greater total bleeding than the younger group (Figure 3). 
Table 4: A summary of the variable Total Bleeding according to Age category and respective measures

\begin{tabular}{|l|l|l|l|l|l|l|}
\hline Variables & Minimum & Q1 & Median & Average & Q3 & Maximum \\
\hline$>59$ years & 953,0 & 1194,0 & 1402,0 & 1407,0 & 1593,0 & 1898,0 \\
\hline$<59$ years & 633,0 & 957,0 & 1074,0 & 1111,0 & 1202,0 & 1630,0 \\
\hline
\end{tabular}

Figure 3: Total Bleeding by Age Group

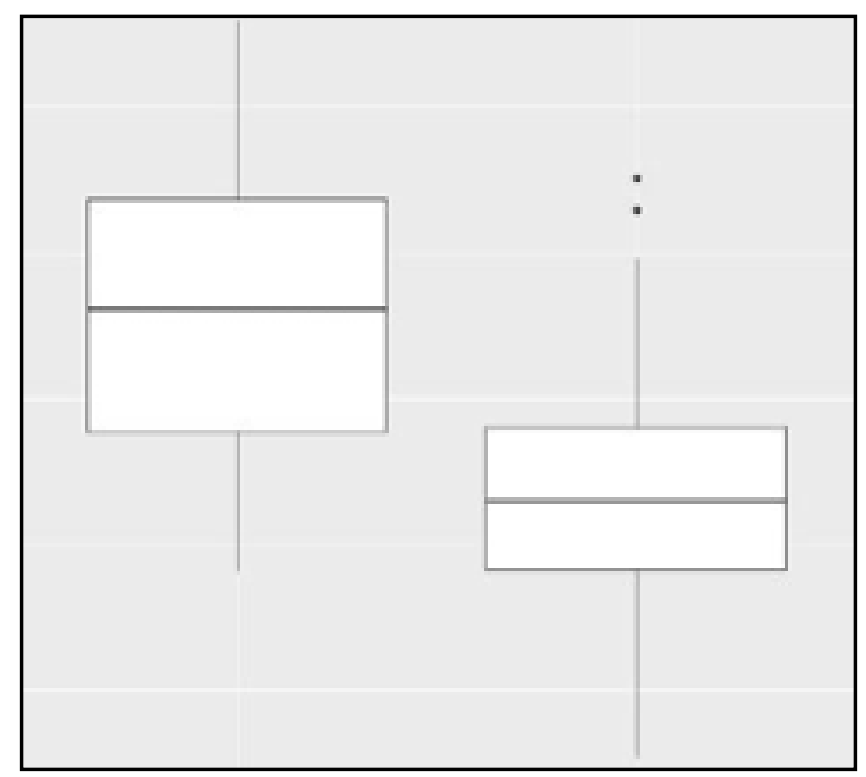

Table 5: A summary of the total bleeding variable by age group according to treatment group and respective measures

\begin{tabular}{|l|l|l|c|l|l|c|}
\hline Groups & Minimum & \multicolumn{1}{|c|}{ Q1 } & Median & Average & Q3 & Maximum \\
\hline Control (above 59 years old) & 1183,0 & 1334,0 & 1516,0 & 1523,0 & 1674,0 & 1898,0 \\
\hline Control (Under 59 years old) & 953,0 & 1104,0 & 1111,0 & 1174,0 & 1212,0 & 1519,0 \\
\hline Test (above 59 years old) & 1064,0 & 1102,0 & 1143,0 & 1207,0 & 1234,0 & 1574,0 \\
\hline Test (Under 59 years old) & 633,0 & 913,0 & 968,0 & 1054,8 & 1189,8 & 1630,0 \\
\hline
\end{tabular}

It was again found that the groups in which the drug was tested were same that obtained lower medians compared to their peers in the Control Group (Figure 4). 
Figure 4: Boxplots of the Total bleeding variable by Age according to treatment group

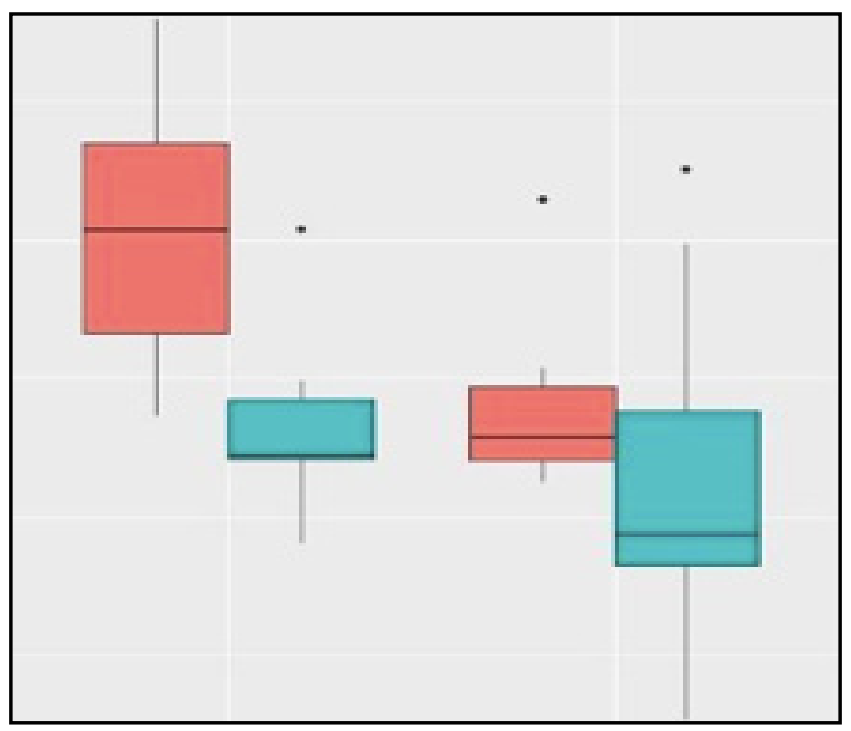

While evaluating only the differences in the total bleeding variable between treatments, i.e., between the Control group and the Test group, the Test group had a lower amount of total bleeding when compared to the Control group. Table 6 shows the summary measures of these two groups.

Table 6: A summary of Total Bleeding per treatmentand respective measures

\begin{tabular}{|l|l|l|l|l|l|l|}
\hline Groups & Minimum & Q1 & Median & Average & Q3 & Maximum \\
\hline Control & 1064,0 & 1191,0 & 1359,0 & 1407,0 & 1594,0 & 1898,0 \\
\hline Test & 633,0 & 951,5 & 1023,0 & 1090,0 & 1194,5 & 1630,0 \\
\hline
\end{tabular}

The Figure 5 representing the measures in Table 6.

Figure 5: Total Bleeding by Treatment used.

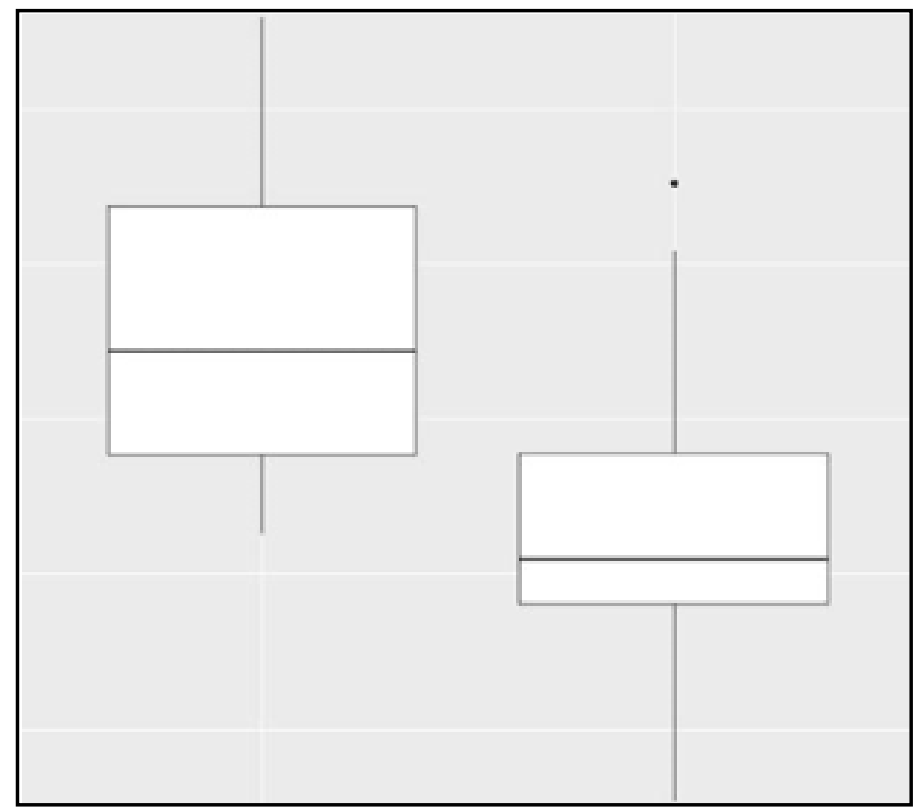




\section{Statistical tests}

Table 7: Student's T test result for comparisons of means of the response variables of the Control group versus Test group.

\begin{tabular}{|l|c|l|}
\hline Variable & Estatistic T & p-value \\
\hline Blood Compresses & 1,7819 & $0,04171^{*}$ \\
\hline Quantity of Blood Compresses & 1,6392 & 0,0554 \\
\hline Collector & 4,1138 & $0,0001^{*}$ \\
\hline Pre-Bleeding & 2,2259 & $0,0163^{*}$ \\
\hline Post-Bleeding & 2,6689 & $0,0067^{*}$ \\
\hline Total Bleeding & 3,7858 & $0,0003^{*}$ \\
\hline
\end{tabular}

T-statistic and P-value of Student's T test according to variables.

* statistically significant value at the $5 \%$ level

We note that the variables Weight of Blood Compresses, Collector and Pre-Bleeding, Post-Bleeding and Total Bleeding showed statistically significant values, i.e., at the $5 \%$ level of significance, they rejected the hypothesis that the means of the Control and Test groups were the same. With this we can confirm that at the level of $5 \%$ of significance, the drug Transamin had an effect in reducing the variables that represented the bleeding of the patients with the exception of the variable Quantity of Blood Compresses.

The Blood Bag variable, which represented the amount of blood transfused to the patient, had an expected response, where a patient who loses more blood needs more transfusion, increasing the average amount of blood received. In the database, the Control group presented 5 patients who used a blood bag obtaining an average of Total Bleeding of $1753.4 \mathrm{ml}$ and needed an average of 1.6 blood bags. In the Test group, only one patient who had $1491 \mathrm{ml}$ total bleeding needed a blood bag.

\section{Discussion}

In United States, approximately 450 thousand total hip arthroplasties are performed annually [11]. Every year we will have an increase in the number of THA due to improvements in techniques, good results and increased life expectancy [12].

An estimate made by Kurtz et al. [13] shows a substantial increase in the number of THA performed annually in the United States, approximately $670 \%$ increase in the year 2030. This gives us an approximate total of 3.5 million hip arthroplasties that same year.

Other important data are the large blood loss from the THA procedure [2][3] and the high rate of blood transfusion resulting from this loss [14]. Based on these data, we were able to predict the size of the economic impact arising from hospital costs. Considering that in the United States the average cost of a red blood cell concentrate is approximately 158 times greater than just one ampoule of tranexamic acid [14][15], the positive effect in reducing bleeding in a THA using ATX would bring considerable savings to the system of health.

With surgical trauma, an activation of the fibrinolytic system occurs at the expense of the release of tissue plasminogen activator (T-PA). The main enzyme that acts in the conversion of plasminogen to plasmin is T-PA. In association, thrombin is also responsible for releasing T-PA in the vascular endothelium, activating fibrinolysis [16]. During surgery there is an increase in fibrinolysis due to greater release of plasmin at the site of vascular damage, caused by surgical stress. Resulting in increased blood loss. Based on this knowledge, the use of tranexamic acid (synthetic inhibitor of fibrinolysis) acts by making a competitive inhibition of plasminogen activation receptors in plasmin [17[18], and due to the nonformation of plasmin, we achieve a delay in fibrinolysis which results in a clot stabilization [19].The choice of this drug for the study was based on its safety profile and on its effectiveness reported in the literature.

Even after several authors have studied the effect of using tranexamic acid in order to reduce bleeding and the need for transfusion of blood products in primary THA, we still have disagreements regarding the dose and ideal time for the administration of the drug in studies [20][21].

In the present study, we observed that there was no difference in bleeding when comparing the operated side. Our results showed that the group that used ATX had a lower mean of perioperative bleeding. Other studies have analyzed this relationship and obtained similar results [22][23]. No complications related to the use of the drug were observed. The Blood Bag variable was proportional to the patient who lost more blood. 
Analyzing the Age Group variable that was created from the median of ages, we observed that the older group had greater total bleeding than the younger group, but this finding will not be explored by this study.

The variables Weight of Blood Compresses, Collector and Pre-Bleeding, Post-Bleeding and Total Bleeding showed statistically significant values. As a result, we can say that the drug Transamin had an effect in reducing the variables that represented the bleeding of patients with the exception of the variable Quantity of Blood Compresses.

\section{Conclusion}

On the basis of above observations and rigorous analysis, we hereby conclude that intravenous ATX applied at a dose of 20mg / $\mathrm{kg}$ after anesthetic induction was effective in satisfactorily reducing blood losses resulting from THA surgery, which consequently resulted in reducing the need for blood transfusion.

\section{References}

1. Spahn DR: Anemia and patient blood management in hip and knee surgery: A systematic review of the literature. Anesthesiology 2010; 113(2): 482-495.

2. Barsoum WK, Klika AK, Murray TG, Higuera C, Lee HH, Krebs VE: Prospective randomized evaluation of the need for blood transfusion during primary total hip arthroplasty with use of a bipolar sealer. J Bone Joint Surg Am 2011; 93(6): 513518.

3. Seo JG, Moon YW, Park SH, Kim SM, Ko KR: The comparative efficacies of intraarticular and IV tranexamic acid for reducing blood loss during total knee arthroplasty. Knee Surg Sports Traumatol Arthrosc 2013; 21(8): 1869-1874.

4. Cushner FD, Friedman RJ, Blodd loss in total knee arthoplasty. Clin Orthop Relat Res. 1991; (269): 98-101

5. Orpen NM, Little C, Walker G, et al. Tranexamic acid reduces early post-operative blood loss after total knee arthoplasty: A prospective randomized controlled trial of 29 patients. The Knee 2006; 13: 106-10.

6. Kirkley SA, Cowles J, Pellegrini VD, Harris CM, Boyd AD, Blumberg N: Blood transfusion and to- tal joint replacement surgery: T helper 2 (TH2) cytokine secretion and clinical outcome. Transfus Med 1998; 8(3): 195-204.

7. Klein HG: How safe is blood, really? Biologicals 2010; 38(1): 100-104.

8. Hynes M, Calder P, Scott G. The use of tranexamic acid to reduce blood loss during total knee arthoplasty. The knee. 2003; 10:375-7.

9. Kagoma YK, Crowther MA, Douketis J, et al. Use of antifibrinolytic therapy to reduce transfusion in patients undergoing orthopedic surgery; A systematic review of randomized trials. Thromb Res. 2009; 123: 687-96.

10. Gandhi R, Evans HMK, Mahomed SR, et al. Tranexamic acid and reduction of blood loss in total knee and hip arthroplasty: A meta-analysis. BMC Research Notes. 2013; 6: 184. doi:http//www.biomedcentral.com/17560500/6/184.

11. Healthcare Cost and Utilization Project (HCUP). HCUP Facts and Figures: Statistic son HospitalBased Care in the United States, 2007 [Internet]. Rockville (MD): Agency for Healthcare Research and Quality (US); 2009.

12. Ritter MA. The anatomical graduated component total knee replacement: Along-term evaluation with 20-year survival analysis. J Bone Joint Surg Br.2009; 91(6): 745-9.

13. Kurtz S, Ong K, Lau E, Mowat F, Halpern M. Projections of primary and revision hip and knee arthroplasty in the United States from 2005 to 2030. J Bone Joint Surg Am. 2007; 89(4): 780-5.

14. Wong J, Abrishami A, El Beheiry H, Mahomed N N, Roderick Davey J, Gandhi R, et al. Topical application of tranexamic acid reduce s post-operative blood loss in total knee arthroplasty: A randomized, controlled trial. J Bone Joint Surg Am. 2010; 92(15): 2503-13.

15. Shander A, Hofmann A, Ozawa S, Theusinger OM, Gombotz H, Spahn DR. Activity-based costs of blood transfusions in surgical patients at four hospitals. Transfusion. 2010; 50(4): 753-65. 
16. Jansen J, Andreica S, Claeys $M$, et al. Use of tranexamic acid for an effective blood conservation strategy after total knee arthroplasty. Br J Anaesth. 1999; 83:596---601.

17. Mac Gillivray RG, Tarabichi SB. Tranexamic acid to reduce blood loss after bilateral total knee arthroplasty --- A prospective, randomized double blind study. J Arth. 2011; 26:24---8.

18. McConnel JS, Shewale S, Munro NA, et al. Reducing blood loss in primary knee arthroplasty: A prospective randomized controlled trial of tranexamic acid and fibrinspray. The Knee. 2012; 19:295---8.

19. Hynes M, Calder P, Scott G. The use of tranexamic acid to reduce blood loss during total knee arthroplasty. The Knee. 2003; 10:375---7.

20. Charoencholvanich K, Siriwattanasakul P. Tranexamic acid reduces blood loss and blood transfusion after TKA: A prospective randomized controlled trial. Clin Ortho p Relat Res. 2011; 469: 2874---80.
21. Gandhi R, Evans HMK, Mahomed SR, et al. Tranexamic acid and reduction of blood loss in total knee and hip arthroplasty: A meta-analysis. BMC Research Notes. 2013; 6:184, doi:http://www.biomedcentral.com/17560500/6/184.

22. Almeida MDC, Albuquerque RP, Palhares GM, Almeida JPC, Barreto JM, Cavanellas N. Evaluation of tranexamic acid in total knee arthroplasty. $r$ and $v$ brasortop. 2018 ; 53 (6): 761-767

23. Volquid D, Zardo RA, Winkler BC, Londero BB, Zanelatto N, Leichtweis GP. Use of tranexamic acid in primary total knee arthroplasty: repercussions on perioperative blood loss. Rev Bras Anestesiol. 2016; 66 (3): 254 --- 258.) 